\title{
A Decade of Journal of Pathology of Nepal: Challenges and opportunities
}

"The Royal Society of London for Improving Natural Knowledge" was the first medical journal and started publishing its Philosophical transactions, the first periodicals since 1665. The journal remained one of the most important European journals until the $19^{\text {th }}$ century. ${ }^{1}$ In the present situation, there are several renowned medical journals with a history of more than a century. Because of these medical journals, the physicians are able to treat the patients optimally. Despite knowing that documentation and dissemination of one's findings in the management of the patients in various disease conditions, physicians from developing and under-developed countries had many difficulties in doing so. However, in the $20^{\text {th }}$ century, medical journals were available to limited physicians. But, in the present day, the internet has completely changed the scenario. A great example is handling of the current COVID-19 pandemic. Robust and accelerated publications regarding this new virus helped to disseminate not only all the possible means of combating the disease and complications associated with it, but also kept updated regarding the efficacy of vaccine against the CoCV-SARS-2 virus. ${ }^{2}$

Contrary to the developed countries, the history of the medical journal is not very long. Journal of Nepal Medical Association is the first Nepalese medical journal. In Nepal, research culture is less developed due to a lack of proper funding and the difficulties in publishing in reputed medical journals. Under the prevailing circumstances, the $7^{\text {th }}$ executive committee of Association of Clinical Pathologists of Nepal (ACPN) led by Dr. JB Thapa felt the need for a medical journal in the filed of pathology. The year 2011 has been a historical moment for us for publishing the first official journal of ACPN "Journal of Pathology of Nepal (JPN)" under the chief editorship of Dr. Gopi Aryal with noteworthy contribution by Dr. Reetu Baral and Dr. Shiva Raj KC. Due to the lack of sufficient numbers of the original article, the editors themselves had to write the articles at the beginning.

It has now been ten years since Dr. Gopi Aryal took over the responsibility as founding Chief Editor. Dr. Shiva Raj $\mathrm{KC}$ took the responsibility of chief editor after a year and he continued it till date. The JPN has become the leading source of sharing original research and cases in pathology not only in our country but also in our neighbouring countries. The journal and its authors are evolving by learning from the past and look forward to betterment in the future. The continuation of excellence of JPN requires effective management to keep the submission and review process efficient and publication lag at a minimum. The essential component of the quality of a biomedical journal is the appropriateness and soundness of the methods used by researchers to conduct their studies. There has been many challenges over the years. We aim to increase the impact factor of JPN, making it more reputable and widely searched. In the past, we struggled for adequate number of manuscript submissions. The situation has changed over the years. The number of manuscript submission from our country is lesser than that of international authors. Due to increasing numbers of submissions and fewer section editors, efficient reviewing process has become a challenge. It is the time to increase the number of issues per annum so as to include more manuscripts in the journal in the days to come.

We as the editors feel a need for a workshop on research writing for young pathologists to re-enforce them to share knowledge and information amongst us which help the pathologist to keep up with all the new knowledge and technologies that are occurring worldwide.

\section{Correspondence:}

Dr. Shiva Raj KC

Dr. Gopi Aryal

Chief Editor

Founding Chief Editor 
References:

1. Marta MM. A brief history of the evolution of the medical research article. Clujul Med. 2015;88(4):567-70. doi: 10.15386/cjmed-560

2. Kaur SP, Gupta V. COVID-19 Vaccine: A comprehensive status report. Virus Res. 2020 Oct 15;288:198114. doi: 10.1016/j.virusres.2020.198114. 